Int. J. Electrochem. Sci., 12 (2017) $3589-3596$

\title{
One-Step Hydrothermal Synthesis of Nickel/Cobalt Double Hydroxide Composite Containing Reduced Graphene Oxide as High Perfomance Electrode Material for Supercapacitor
}

\author{
Guoping Wang ${ }^{1, *}$, Hui Jia ${ }^{1}$, Liwei Zhu ${ }^{1}$, Meirong Li $^{2}$, Yurong Ren ${ }^{2, *}$, Yanjie Wang ${ }^{3}$ \\ ${ }^{1}$ College of Chemistry and Chemical Engineering, University of South China, Hengyang, Hunan \\ 421001, China \\ ${ }^{2}$ School of Materials Science and Engineering, Jiangsu Collaborative Innovation Center for \\ Photovoltaic Science and Engineering, Changzhou University, Changzhou 213164, China. \\ ${ }^{3}$ Department of Chemical and Biological Engineering, University of British Columbia, 2360 East \\ Mall, Vancouver, BC Canada V6T1Z3 \\ *E-mail: ryrchem@163.com, wgpcd@ aliyun.com, wgpcd@ yahoo.com.cn
}

doi: $10.20964 / 2017.05 .77$

Received: 5 December 2016 / Accepted: 28 February 2017 / Published: 12 April 2017

Nickel/cobalt double hydroxide composite containing reduced graphene oxide (Ni/Co-DH-RGO) with high electrochemical performances has been prepared by hydrothermal one-step method accompanied with using hexamethylene tetramine (HMT) as homogeneous precipitating agent and its hydrolysis product for reducing graphene oxide. X-ray diffraction pattern displays that Ni/Co-DH-RGO exists as a composite of $\alpha-\mathrm{Ni}(\mathrm{OH})_{2}-\beta-\mathrm{Co}(\mathrm{OH})_{2}$ and reduced graphene oxide. Infrared spectrum shows that the typical peaks of carboxyl and expoxy group in graphene oxide are significantly weakened after the hydrothermal reaction. Scanning electron microscope image shows Ni/Co-DH-RGO takes on hierarchical morphology. The as-prepared Ni/Co-DH-RGO has a specific capacitance of $2120 \mathrm{~F} \mathrm{~g}^{-1}$ at a current density of $1 \mathrm{~A} \mathrm{~g}^{-1}$ and $1569.8 \mathrm{~F} \mathrm{~g}^{-1}$ at the current density of $8 \mathrm{~A} \mathrm{~g}^{-1}$.

Keywords: Hydrothermal one-step synthesis; Hexamethylene tetramine; Nickel/cobalt double hydroxide composite; supercapacitor; electrode material.

\section{$\underline{\text { FULL TEXT }}$}

(C) 2017 The Authors. Published by ESG (www.electrochemsci.org). This article is an open access article distributed under the terms and conditions of the Creative Commons Attribution license (http://creativecommons.org/licenses/by/4.0/). 